\title{
INOCULAÇÃO DE Azospirillum amazonense EM DOIS GENÓTIPOS DE MILHO SOB DIFERENTES REGIMES DE NITROGENIOO ${ }^{(1)}$
}

\author{
Fábio Bueno dos Reis Junior ${ }^{(2)}$, Cynthia Torres de Toledo \\ Machado $^{(2)}$, Altair Toledo Machado ${ }^{(2)}$ \& Ladaslav Sodek ${ }^{(3)}$
}

\begin{abstract}
RESUMO
A adaptabilidade de genótipos de milho a ambientes onde os nutrientes não estejam prontamente disponíveis pode ser relacionada com a adaptação à predominância, nos solos, das formas de $\mathrm{N}$ nítrica e amoniacal e à associação com microrganismos benéficos como as bactérias diazotróficas e, ou, promotoras de crescimento de plantas. $O$ objetivo deste trabalho foi verificar o comportamento de dois híbridos intervarietais de milho sob diferentes doses e formas de $\mathrm{N}$, assim como o efeito da inoculação com Azospirillum amazonense, em um ensaio em casa de vegetação, utilizando vasos preenchidos com vermiculita e solução nutritiva de Hoagland como fonte de nutrientes. O delineamento experimental foi de blocos ao acaso em esquema fatorial, constituindo os tratamentos em: dois híbridos intervarietais, H1 (Carioca x Eldorado) e H2 (Palha Roxa ES x Sol da Manhã); plantas inoculadas ou não inoculadas com $A$. amazonense, e três regimes de $\mathrm{N}$, conforme doses e proporções seguintes: $126 \mathrm{mg}_{\text {semana }}{ }^{-1}$ de $\mathrm{N}\left(75 \% \mathrm{NH}_{4}{ }^{+}: 25 \% \mathrm{NO}_{3}{ }^{-}\right)$;

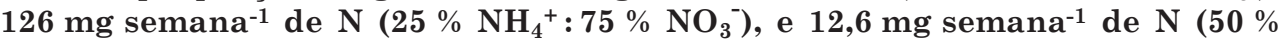
$\mathrm{NH}_{4}{ }^{+}: 50 \% \mathrm{NO}_{3}{ }^{-1}$ ). Vinte e cinco dias após o plantio, as plantas foram separadas em raiz e parte aérea para determinação da matéria seca, conteúdos totais de $\mathrm{N}$ e $\mathrm{P}$, atividade das enzimas nitrato redutase e glutamina sintetase e açúcares solúveis totais. O híbrido $\mathrm{H} 1$, mais eficiente em avaliações preliminares em campo, produziu mais matéria seca e apresentou maior eficiência na utilização de N e P. Plantas que receberam a maior dose de $\mathrm{N}$, independentemente do predomínio da forma nítrica ou amoniacal, apresentaram maior acúmulo de $\mathrm{N}$ (nas raízes e parte aérea) e P (na parte aérea) e maior índice de utilização de P. Com o predomínio da forma amoniacal, observou-se incremento na produção de matéria seca da parte aérea e
\end{abstract}

\footnotetext{
(1) Apoio financeiro do CNPq (processo 478026/2003-0) e do Programa Biodiversidade Brasil-Itália. Recebido para publicação em julho de 2007 e aprovado em fevereiro de 2008.

(2) Pesquisador da Embrapa Cerrados, BR 020, Km 18, Caixa Postal 08223, CEP 73310-970 Planaltina (DF). E-mails: fabio@cpac.embrapa.br; cynthia@cpac.embrapa.br; altair@cpac.embrapa.br

${ }^{(3)}$ Professor do Departamento de Fisiologia Vegetal, Universidade de Campinas -UNICAMP. Cidade Universitária Zeferino Vaz, Caixa Postal 6011, CEP 13083-875 Campinas (SP). E-mail: lsodek@unicamp.br
} 
na atividade da glutamina sintetase, bem como decréscimo na concentração de açúcares solúveis totais nas raízes. A inoculação com $A$. amazonense promoveu maior produção de matéria seca e acúmulo de $\mathrm{N}$ nas raízes.

Termos para indexação: bactérias diazotróficas, bactérias promotoras do crescimento, Zea mays.

\title{
SUMMARY: INOCULATION OF Azospirillum amazonense IN TWO MAIZE GENOTYPES UNDER DIFFERENT NTREATMENTS
}

\begin{abstract}
The adaptability of maize genotypes to environments where nutrients are not readily available may be related to an adaptation to the predominance of the soil nitric and ammoniacal forms of $N$ and to the association with beneficial microorganisms such as diazotrohpic bacteria and/or plant growth promoters. The objective of this study was to evaluate the response of two maize intervarietal hybrids to different nitrogen doses and forms as well as the effect of inoculation with A. amazonense. The experiment was carried out in a greenhouse with pots filled with vermiculite and Hoagland nutrient solution. A three-factor randomized complete block design was used with treatments arranged in a factorial scheme represented by: H1 (Carioca $x$ Eldorado) and H2 (Palha Roxa ES x Sol da Manhã) intervarietal hybrids; plants inoculated or not with A. amazonense; and three nitrogen proportions and doses: $126 \mathrm{mg}_{\text {week }}{ }^{-1}$ of $\mathrm{N}\left(75 \% \mathrm{NH}_{4}^{+}: 25 \% \mathrm{NO}_{3}^{-}\right) ; 126 \mathrm{mg}^{-} \mathrm{week}^{-1}$ of $\mathrm{N}\left(25 \% \mathrm{NH}_{4}^{+}: 75 \% \mathrm{NO}_{3}^{-}\right)$; and $12.6 \mathrm{mg}^{-}$week $^{-1}$ of $\mathrm{N}\left(50 \% \mathrm{NH}_{4}^{+}: 50 \% \mathrm{NO}_{3}^{-}\right)$. After 25 days of growth the plant roots and shoots were separated for the determination of dry matter production, total $N$ and $P$ content, nitrate reductase and glutamine synthetase activity and total soluble sugars. The H1 hybrid, considered more efficient in preliminary field evaluations, produced greater dry matter and was more efficient in $N$ and $P$ utilization. In plants that received the highest $N$ dose, independently of the predominance of the ammoniacal or nitric forms, the $N$ (roots and shoots) and $P$ (shoots) accumulation as well as the $P$ utilization index were higher. Under the predominance of the ammonium- $N$ plants grew more and the glutamine synthetase activity was increased, while the concentration of root total soluble sugars was lowered. The inoculation with A. amazonense resulted in higher root dry matter production and $N$ accumulation.
\end{abstract}

Index terms: diazotrophic bacteria, plant growth-promoting bacteria, Zea mays.

\section{INTRODUÇÃO}

O milho tem grande importância social, econômica e cultural no Brasil. Aproximadamente, 12 milhões de hectares são cultivados, em sua maioria, por pequenos e médios agricultores (Fancelli \& DouradoNeto, 2000). Essa cultura geralmente é influenciada por problemas de estresse ambiental, dentre os quais se destaca a baixa fertilidade dos solos, que, em sua maioria, apresentam deficiência de N. Segundo Fancelli (2003), tal deficiência pode reduzir o rendimento de grãos entre 14 e 80 \%.

A identificação, a seleção e o uso de genótipos de milho mais tolerantes à deficiência de $\mathrm{N}$ e eficientes na aquisição deste elemento constitui estratégia importante. Nesse sentido, deve ser considerada a busca por genótipos que formem associações mais eficientes com bactérias diazotróficas e, ou, promotoras de crescimento. Sabe-se que existem interações entre o N e essas bactérias na assimilação e utilização desse nutriente pelas plantas. Ferreira et al. (1987) observaram, por exemplo, que bactérias do gênero Azospirillum podem atuar no crescimento vegetal por meio da redução do $\mathrm{NO}_{3}{ }^{-}$nas raízes das plantas. Desse modo, as plantas não gastariam energia para reduzir o nitrato até amônia e essa energia poderia ser canalizada para outros processos vitais do metabolismo. Para Machado et al. (1998a), tais bactérias podem exercer alguma influência na atividade da glutamina sintetase em raízes de plantas de milho. Em relação à contribuição da fixação biológica de $\mathrm{N}_{2}$, Garcia de Salomone et al. (1996) relataram que algumas variedades de milho cultivadas em vasos a céu aberto puderam fixar por volta de $58 \%$ do seu requerimento em N, quando inoculadas com Azospirillum.

Existem variações entre genótipos de milho na resposta ao $\mathrm{N}$ (Alfoldi et al., 1992), assim como interações entre o milho e bactérias diazotróficas e, 
ou, promotoras de crescimento são dependentes dos genótipos da planta e dos microrganismos envolvidos nessas associações (Garcia de Salomone \& Döbereiner, 1996). Dentre os microrganismos diazatróficos encontrados em associações com cereais e gramíneas, as espécies de Azospirillum constituem um dos grupos mais bem estudados atualmente, sendo numerosos os trabalhos sobre sua ecologia, fisiologia e genética (Baldani et al., 1997; Bashan \& Holguin, 1997).

A interação positiva entre estas bactérias e o milho tem sido demonstrada por vários autores e, embora ainda não seja prática agrícola consolidada, levantamentos de diversos experimentos realizados em vários países mostram que a inoculação com Azospirillum resultou, na maioria dos casos, em aumento de matéria seca, de produção de grãos e de acúmulo de $\mathrm{N}$ nas plantas inoculadas, particularmente quando envolveu genótipos não melhorados em presença de baixa disponibilidade de N (Okon \& Vanderleyden, 1997).

Embora o gênero Azospirillum seja constituído de sete espécies, a quase totalidade dos experimentos de inoculação, feitos em mais de 20 anos, refere-se a $A$. brasilense, seguida de A. lipoferum, com apenas alguns poucos trabalhos realizados no Brasil com estirpes de A. amazonense (Baldani et al., 1999). Estudos que envolvem a espécie $A$. amazonense são interessantes, pois, dentre as características dessa espécie, destaca-se a adaptabilidade a $\mathrm{pH}$ ácido (Baldani et al., 1997), característica comum à maioria dos solos brasileiros.

No Brasil, poucos estudos têm enfocado as interações entre genótipos de milho, $\mathrm{N}$ e bactérias diazotróficas e, ou, promotoras de crescimento. A adaptabilidade de genótipos de milho a ambientes onde os nutrientes não estejam prontamente disponíveis pode ser relacionada com a adaptação à predominância, nos solos, das formas de $\mathrm{N}$ nítrica e amoniacal e à associação com microrganismos benéficos como as bactérias diazotróficas e promotoras de crescimento de plantas.

O objetivo deste trabalho foi verificar o comportamento de dois híbridos intervarietais contrastantes sob diferentes doses e formas de $\mathrm{N}$, assim como o efeito da inoculação com a bactéria $A$. amazonense em um ensaio em casa de vegetação.

\section{MATERIAL E MÉTODOS}

Este experimento foi realizado em março de 2005, em casa de vegetação, no Departamento de Fisiologia Vegetal da Unicamp, com dois híbridos intervarietais de milho, H1 (Carioca x Eldorado) e H2 (Palha Roxa x Sol da Manhã). As variedades locais nestes cruzamentos, Carioca e Palha Roxa ES, foram obtidas no período de 1990-1991 junto a organizações de agricultores familiares participantes da Rede Milho, estabelecida pela parceria entre a AS-PTA e a Embrapa (Soares et al., 1998). Estas variedades foram avaliadas para condições de estresses abióticos em diferentes regiões do País (Machado et al., 1998b), quando a variedade local Carioca apresentou-se com alto potencial produtivo. A variedade Eldorado vem sendo selecionada por mais de 15 anos e tem-se destacado em diferentes ensaios de milho em sistemas orgânicos de produção (Machado et al., 2006). A variedade Palha Roxa ES apresentou forte interação genótipo-ambiente e a variedade Sol da Manhã foi selecionada para eficiência no uso de $\mathrm{N}$ num esquema de melhoramento participativo (Machado, 2000; Machado \& Fernandes, 2001). Em um ensaio da Embrapa Cerrados no ano de 2003, os híbridos H1 e H2 apresentaram-se contrastantes para o caráter produção de grãos (dados não publicados), sendo esta a razão para a sua escolha como testadores para este trabalho.

Após a pré-germinação das sementes, oito plântulas foram transferidas para vasos com capacidade para $3 \mathrm{~L}$ preenchidos com vermiculita lavada. No momento do plantio, foi feita a inoculação, junto a cada plântula, com $1 \mathrm{~mL}$ de meio de cultura líquido LGI (Silva, 2005) que continha a estirpe LIV 205 de $A$. amazonense $\left(10^{8}\right.$ células $\left.\mathrm{mL}^{-1}\right)$. Essa estirpe foi selecionada de acordo com a produção de ácido indol-acético e promoção de crescimento baseado em resultados de estudos anteriores (Rolim et al., 2005).

Uma semana após o plantio, foi feito um desbaste, visando à permanência de quatro plantas por vaso. Durante o ensaio, foram aplicados nos vasos, duas vezes por semana, $300 \mathrm{~mL}$ de solução nutritiva de Hoagland modificada (Machado et al., 1998a), com três regimes de $\mathrm{N}$ distintos, variando as proporções e as doses de $\mathrm{N}$ da seguinte forma: $126 \mathrm{mg}^{\text {semana }}{ }^{-1} \mathrm{de} \mathrm{N}$ $\left(75 \% \mathrm{NH}_{4}^{+}: 25 \% \mathrm{NO}_{3}{ }^{-}\right) ; 126 \mathrm{mg}$ semana ${ }^{-1}$ de $\mathrm{N}(25 \%$ $\left.\mathrm{NH}_{4}{ }^{+}: 75 \% \mathrm{NO}_{3}{ }^{-}\right)$, e $12,6 \mathrm{mg}$ semana ${ }^{-1}$ de $\mathrm{N}(50 \%$ $\left.\mathrm{NH}_{4}^{+}: 50 \% \mathrm{NO}_{3}^{-}\right)$. Três soluções de Hoagland modificadas ( $\mathrm{pH}$ médio de 5,13$)$ foram usadas para a formulação dos diferentes regimes de $\mathrm{N}$, em que somente as formas de $\mathrm{N}$ e suas concentrações foram alteradas. Foram preparadas as soluções básicas I, II e III, tendo a solução I $100 \%$ do N fornecido na forma nítrica, a solução II $100 \%$ do $\mathrm{N}$ na forma amoniacal e a III sem N (Quadro 1). Nos vasos que receberam o tratamento, $75 \% \mathrm{NO}_{3}{ }^{-}: 25 \% \mathrm{NH}_{4}{ }^{+}$ (126 mg semana ${ }^{-1}$ de N), $75 \%$ do volume total de solução aplicado foi proveniente da solução I e os $25 \%$ restantes da solução II. Nos vasos que receberam o tratamento $25 \% \mathrm{NO}_{3}{ }^{-}: 75 \% \mathrm{NH}_{4}{ }^{+}(126 \mathrm{mg}$ semana${ }^{1}$ de N), $25 \%$ do volume total de solução aplicado foi proveniente da solução I e os 75 \% restantes da solução II. Finalmente, nos vasos que receberam o tratamento $50 \% \mathrm{NO}_{3}{ }^{-}: 50 \% \mathrm{NH}_{4}{ }^{+}\left(12,6 \mathrm{mg}\right.$ semana ${ }^{-1}$ de $\left.\mathrm{N}\right)$, $10 \%$ do volume total de solução aplicado foi proveniente da solução I, outros 10 \% da solução II e os $80 \%$ restantes do volume total aplicado foram provenientes da solução III, sem N. 
Quadro 1. Composição das três soluções nutritivas, denominadas solução I $\left(100 \% \mathrm{NO}_{3}^{-}\right)$, II $(100 \%$ $\mathrm{NH}_{4}^{+}$) e III (sem N), usadas para a formulação dos diferentes regimes de $\mathrm{N}$ avaliados

Macronutriente Solução I Solução II Solução III

Concentração do sal $\left(\mathrm{mg} \mathrm{L}^{-1}\right)$

$\begin{array}{lr}\mathrm{Ca}\left(\mathrm{NO}_{3}\right)_{2} .4 \mathrm{H}_{2} \mathrm{O} & 1.180 \\ \mathrm{KNO}_{3} & 505 \\ \mathrm{KH}_{2} \mathrm{PO}_{4} & 136 \\ \mathrm{MgSO}_{4} \cdot 7 \mathrm{H}_{2} \mathrm{O} & 492 \\ \left(\mathrm{NH}_{4}\right)_{2} \mathrm{SO}_{4} & \\ \mathrm{CaCl}_{2} .2 \mathrm{H}_{2} \mathrm{O} & \\ \mathrm{K}_{2} \mathrm{SO}_{4} & \\ \mathrm{CaSO} & \\ \mathrm{KCl} & \\ \mathrm{KC} & \mathrm{O}\end{array}$

180

505

136

492

136

492

990

735

- 348

$\mathrm{KCl}$

372,5

344

Micronutriente

\begin{tabular}{lccc}
$\mathrm{H}_{3} \mathrm{BO}_{3}$ & 2,04 & 2,04 & 2,04 \\
$\mathrm{MnCl}_{2} \cdot 4 \mathrm{H}_{2} \mathrm{O}$ & 2,34 & 2,34 & 2,34 \\
$\mathrm{ZnSO}_{4} \cdot 7 \mathrm{H}_{2} \mathrm{O}$ & 0,88 & 0,88 & 0,88 \\
$\mathrm{CuSO}_{4} \cdot 5 \mathrm{H}_{2} \mathrm{O}$ & 0,20 & 0,20 & 0,20 \\
$\mathrm{Na}_{2} \mathrm{MoO}_{4} \cdot 2 \mathrm{H}_{2} \mathrm{O}$ & 0,26 & 0,26 & 0,26 \\
$\mathrm{Fe} \mathrm{SO}_{4} \cdot 7 \mathrm{H}_{2} \mathrm{O}$ & 24,1 & 24,1 & 24,1 \\
EDTA & 25,1 & 25,1 & 25,1 \\
\hline
\end{tabular}

A umidade dos vasos foi mantida em torno da capacidade de campo com irrigações periódicas.

O delineamento experimental adotado foi o de blocos ao acaso em esquema fatorial 2 (híbridos de milho) $\mathrm{x}$ 2 (plantas inoculadas e não inoculadas) x 3 (regimes de N), com quatro repetições. Os procedimentos estatísticos aplicados aos dados do experimento compreenderam análise de variância e teste de médias (Duncan $5 \%$ ).

Depois de 25 dias, as plantas foram separadas em raiz e parte aérea para a determinação da matéria seca, conteúdos totais de $\mathrm{N}$ e de $\mathrm{P}$, atividade das enzimas nitrato redutase (NR) e glutamina sintetase (GS) e açúcares solúveis totais (AST).

A matéria seca das plantas foi determinada após secagem em estufa e os teores de $\mathrm{N}$ e de $\mathrm{P}$ foram determinados de acordo com o método descrito em Embrapa (1999). Os índices de eficiência de utilização de $\mathrm{N}$ e de $\mathrm{P}$, razão entre a matéria seca e o acúmulo desses nutrientes nas plantas, foram calculados de acordo com Machado et al. (2001).

A atividade da enzima NR foi determinada nas folhas utilizando-se o método adaptado por Majerowicz et al. (2002). Folhas frescas foram picotadas e 0,5 g foi colocado em seringas hipodérmicas de volume de $10 \mathrm{~mL}$. Adicionaram-se $4 \mathrm{~mL}$ do meio de reação tampão fosfato $\left(\mathrm{K}_{2} \mathrm{HPO}_{4} 0,05 \mathrm{~mol} \mathrm{~L}-1\right.$ pH 7,5; $\mathrm{KNO}_{3}$ $0,05 \mathrm{~mol} \mathrm{~L}^{-1}+\mathrm{n}$-propanol a $1 \%$ ) e fechou-se a saída da seringa com o dedo, puxando o êmbolo por três vezes para fazer vácuo com o material vegetal submerso no meio. As seringas foram seladas e guardadas no escuro por $30 \mathrm{~min}$ a $30^{\circ} \mathrm{C}$. Após a passagem por filtro $\mathrm{GF} / \mathrm{C}$ (24 mm), uma alíquota de $2 \mathrm{~mL}$ dessa solução foi transferida para tubo de ensaio para dosagem do nitrito, produto da reação. Para este fim, aos tubos foram acrescentados $1 \mathrm{~mL}$ de sulfanilamida $1 \%$ e $1 \mathrm{~mL}$ de $\mathrm{N}$-(naftil)-etilenodiamina.2HCl. Os tubos foram agitados e permaneceram em repouso por $30 \mathrm{~min}$. A absorbância foi lida a $540 \mathrm{~nm}$ e a concentração de nitrito calculada a partir de curva-padrão estabelecida com quantidades de $\mathrm{NO}_{2}^{-}$na faixa de 0,0059 a $0,1 \mu \mathrm{mol}$.

Para determinar a atividade da GS (Machado et al., 1998a), amostras de $1 \mathrm{~g}$ de raízes foram trituradas em almofariz em $5 \mathrm{~mL}$ de tampão de extração (Tris $\mathrm{HCl} 100 \mathrm{mmol} \mathrm{L}^{-1}$; ditiotreitol (DTT) $1 \mathrm{mmol} \mathrm{L}^{-1}$; ácido glutâmico $5 \mathrm{mmol} \mathrm{L}^{-1}$; $\mathrm{MgCl}_{2} 10 \mathrm{mmol} \mathrm{L}^{-1}$ e glicerol $10 \%$ ). Esse extrato foi filtrado em gaze umedecida e centrifugado a $10.000 \mathrm{rpm}$ por $20 \mathrm{~min}$ a $4{ }^{\circ} \mathrm{C}$. Uma alíquota de $2 \mathrm{~mL}$ do sobrenadante foi retirada e passada por uma coluna de dessalinização PD 10, no interior de câmara fria mantida em $4^{\circ} \mathrm{C}$. Em seguida, $1 \mathrm{~mL}$ da fração protéica dessalinizada foi misturado a $1 \mathrm{~mL}$ de meio de reação (ácido glutâmico $100 \mathrm{mmol} \mathrm{L}^{-1}$; hidroxilamina $\left(\mathrm{NH}_{2} \mathrm{OH} . \mathrm{HCl}\right) 8 \mathrm{mmol} \mathrm{L}^{-1}$; ATP $8 \mathrm{mmol} \mathrm{L}-1 ; \mathrm{MgCl}_{2} 16 \mathrm{mmol} \mathrm{L}^{-1}$ e Tris $\mathrm{HCl} 100 \mathrm{mmol} \mathrm{L}^{-1}$ $\mathrm{pH} 7,8)$. Desta mistura, $500 \mu \mathrm{L}$ foram retirados para constituir o ponto inicial da atividade enzimática (T0) e a reação foi paralisada com $600 \mu \mathrm{L}$ do reagente $\mathrm{FeCl}_{3}$ $\left(\mathrm{HCl}\right.$ 0,67 $\mathrm{mol} \mathrm{L}^{-1}$; ácido tri-cloro-acético TCA

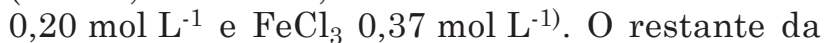
mistura foi incubado em banho-maria a $30^{\circ} \mathrm{C}$, e alíquotas de $500 \mu \mathrm{L}$ foram retiradas em intervalos de 45 min, adicionando-se o reagente $\mathrm{FeCl}_{3}$ para paralisar a reação. A enzima GS sintetiza a reação ácido glutâmico $+\mathrm{NH}_{2} \mathrm{OH}+\mathrm{ATP}$, que, na presença do cofator $\mathrm{Mg}$, produzirá o $\gamma$ - glutamil hidroxamato $+\mathrm{ADP}+\mathrm{Pi}+$ $\mathrm{H}_{2} \mathrm{O}$. A atividade foi, portanto, determinada pela concentração de glutamil hidroxamato, determinada por espectrofotometria, sendo as densidades óticas dos padrões e amostras lidas a $535 \mathrm{~nm}$.

Para avaliar a dosagem dos AST nas raízes, foi utilizado, em primeiro lugar, o método de extração descrito por Bieleski \& Turner (1966). O método utilizado para a dosagem desses açúcares foi baseado em Graham \& Smydzuk (1965). Tomou-se 0,2 mL do extrato de cada amostra ao qual foi adicionado 0,8 mL de água destilada em tubos de ensaio que foram mantidos em banho de gelo. Três $\mathrm{mL}$ de solução de antrona $\left(0,15 \%\right.$ em $\mathrm{H}_{2} \mathrm{SO}_{4}$ concentrado) resfriada foram adicionados a cada tubo que foi tampado com uma esfera de vidro. Após $15 \mathrm{~min}$, os tubos foram agitados e incubados em banho-maria a $90{ }^{\circ} \mathrm{C}$ durante 20 min. Em seguida, os tubos foram transferidos para o escuro e, após atingir a temperatura ambiente, foram novamente agitados e a densidade ótica dos padrões (15-150 $\mu \mathrm{g} \mathrm{mL}^{-1}$ de glicose) e amostras foi medida a $620 \mathrm{~nm}$ contra o branco. 


\section{RESULTADOS E DISCUSSÃO}

Não houve interação entre os híbridos de milho e as formas/doses de $\mathrm{N}$ utilizadas em relação ao acúmulo de matéria seca pelas plantas (Quadro 2). Apesar disso, sabe-se que diferentes genótipos de milho podem responder de maneira variada ao nitrato (Purcino et al., 1990) e amônio (Magalhães et al., 1993). Segundo Magalhães et al. (1993), as respostas de plantas de milho à aplicação de $\mathrm{N}$ na forma de $\mathrm{NH}_{4}{ }^{+}$podem ser indicadas para a seleção de genótipos mais eficientes na assimilação deste nutriente.

Verificou-se maior produção de matéria seca da parte aérea em plantas de milho que tiveram a forma amoniacal predominante no $\mathrm{N}$ aplicado (Quadro 3). Plantas que tiveram a aplicação de N com predomínio da forma nítrica também mostraram maior acúmulo de matéria seca da parte aérea em relação às plantas que receberam proporção igual das formas de $\mathrm{N}$ na sua menor dose. Para produção de matéria seca de raízes, esses efeitos não foram observados. Majerowicz et al. (2002) também mostraram que o acúmulo de matéria seca na parte aérea de plantas de milho foi influenciado pelas doses de $\mathrm{N}$, em contraste com o que foi observado no sistema radicular. Esses autores concluíram que a deficiência de $\mathrm{N}$ alterou o crescimento da parte aérea, tendo um impacto não-significativo sobre o sistema radicular.

O híbrido H1, tido como mais eficiente de acordo com ensaios preliminares de competição em campo, apresentou maior produção de matéria seca de raízes em relação ao H2 (Quadro 4). Em relação à parte aérea, não houve diferenças significativas entre os dois genótipos (Quadro 2).
Não foi observado efeito da inoculação com $A$. amazonense na produção de matéria seca da parte aérea (Quadro 2). Entretanto, plantas inoculadas apresentaram maior produção de matéria seca de raízes, quando comparadas à de plantas não inoculadas (Quadro 5). Trabalhos relativos à inoculação do milho com $A$. amazonense não são tão freqüentes, porém, Lee et al. (1989) e Silva (2005) apresentaram resultados que podem ser tomados como exemplos do efeito positivo da inoculação dessa espécie em plantas de milho.

Quando os estudos com as associações entre plantas e Azospirillum tiveram seu início, acreditavase que os benefícios obtidos eram essencialmente derivados da fixação biológica de $\mathrm{N}_{2}$ (Dobbelaere et al., 2001); no entanto, estudos posteriores demonstraram que os efeitos positivos proporcionados por estes microrganismos eram, principalmente, derivados de alterações morfológicas e fisiológicas nas raízes das plantas inoculadas, acarretando um incremento na absorção de água e nutrientes (Okon \& Vanderleyden, 1997). Provavelmente, a maior produção de matéria seca e o acúmulo de nutrientes por plantas inoculadas sejam devidos à produção de substâncias promotoras de crescimento pelas bactérias. Bashan \& Holguin (1997) relataram ser óbvio que fitormônios, principalmente o ácido indol-acético (AIA), excretados por Azospirillum desempenham papel essencial na promoção do crescimento de plantas em geral.

$\mathrm{O}$ acúmulo de $\mathrm{N}$ nas plantas, tanto na parte aérea quanto nas raízes, não foi influenciado pelo predomínio da forma nítrica ou amoniacal, porém foi bastante reduzido quando a menor dose de $\mathrm{N}$, em proporção igual de $\mathrm{NO}_{3}{ }^{-}$e de $\mathrm{NH}_{4}^{+}$, foi aplicada (Quadro 3). Plantas inoculadas com A. amazonense apresentaram maior conteúdo de $\mathrm{N}$ nas raízes (Quadro 5). O

Quadro 2. Análises de variância para produção de matéria seca da parte aérea (MSPA) e raízes (MSR), conteúdo de $\mathrm{N}$ da parte aérea (NPA) e raízes (NR), conteúdo de $\mathrm{P}$ da parte aérea (PPA) e raízes (PR), eficiência de utilização de $N$ (EUN) e P (EUP), atividade da nitrato redutase (ANR), atividade da glutamina sintetase (AGS) e açúcares solúveis totais (AST) de dois híbridos intervarietais de milho submetidos a diferentes proporções e doses de $\mathrm{N}$ e inoculação com Azospirillum amazonense

\begin{tabular}{|c|c|c|c|c|c|c|c|c|c|c|c|c|}
\hline \multirow{2}{*}{$\begin{array}{l}\text { Fonte de } \\
\text { Variação }\end{array}$} & \multirow[b]{2}{*}{ GL } & \multicolumn{11}{|c|}{$\mathrm{QM}$} \\
\hline & & MSPA & MSR & NPA & NR & PPA & PR & EUN & EUP & ANR & AGS & $\mathrm{AST}$ \\
\hline Blocos & 3 & $0,53^{* *}$ & $0,17^{* *}$ & $262,21^{*}$ & 23,27 & $11,37^{* *}$ & $1,01^{* *}$ & $0,005^{* *}$ & $0,084^{* *}$ & 0,17 & $66,30 * *$ & 194,07 \\
\hline Híbridos (H) & 1 & 0,20 & $0,14^{*}$ & 181,73 & 31,59 & 1,76 & $0,53^{*}$ & 0,004 & 0,085 & 0,00 & 9,05 & 402,12 \\
\hline Regime de $\mathrm{N}(\mathrm{N})$ & 2 & $2,33^{* *}$ & 0,00 & $6377,05^{* *}$ & $178,56^{* *}$ & $38,02^{* *}$ & 0,30 & $0,011^{* *}$ & $0,188^{* *}$ & $7,57^{* *}$ & $91,04^{* *}$ & $1809,62^{* *}$ \\
\hline $\mathrm{H} \times \mathrm{N}$ & 2 & 0,03 & 0,01 & 165,21 & 2,67 & 1,77 & 0,20 & 0,001 & 0,001 & 0,01 & 9,95 & 50,06 \\
\hline Inoculação (I) & 1 & 0,08 & $0,12^{*}$ & 81,09 & $48,16^{*}$ & 3,54 & 0,22 & 0,000 & 0,014 & 0,03 & 1,18 & 12,29 \\
\hline $\mathrm{H} \times \mathrm{I}$ & 1 & 0,21 & 0,07 & 132,72 & 13,71 & 3,21 & 0,12 & 0,001 & 0,058 & 0,00 & 7,41 & 283,19 \\
\hline $\mathrm{N} \times \mathrm{I}$ & 2 & 0,11 & 0,02 & 47,79 & 7,16 & 2,32 & 0,08 & 0,001 & 0,011 & 0,02 & 10,76 & $687,72^{*}$ \\
\hline $\mathrm{H} \times \mathrm{N} \times \mathrm{I}$ & 2 & 0,11 & 0,05 & 85,34 & 0,24 & 4,50 & 0,02 & 0,001 & 0,027 & 0,21 & 2,11 & 19,47 \\
\hline Resíduo & 33 & 0,09 & 0,02 & 85,21 & 8,55 & 2,24 & 0,10 & 0,001 & 0,017 & 0,12 & 6,53 & 168,12 \\
\hline CV (\%) & & 21,14 & 19,28 & 23,13 & 27,36 & 21,05 & 27,05 & 22,83 & 21,21 & 27,79 & 33,72 & 27,30 \\
\hline
\end{tabular}

*, **: Significativos a 5 e $1 \%$. 
Quadro 3. Efeito da aplicação de diferentes proporções e doses de N sobre a produção de matéria seca da parte aérea (MSPA), conteúdo de $\mathrm{N}$ da parte aérea (NPA) e raízes (NR), conteúdo de $P$ da parte aérea (PPA), eficiência de utilização de N (EUN) e P (EUP), atividade da nitrato redutase (ANR), atividade da glutamina sintetase (AGS) e açúcares solúveis totais (AST) em plantas de milho cultivadas em casa de vegetação e colhidas 25 dias após o plantio

\begin{tabular}{|c|c|c|c|c|c|c|c|c|c|}
\hline Regimes de $\mathrm{N}$ & MSPA & NPA & NR & PPA & EUN & EUP & ANR & AGS & AST \\
\hline & g/vaso & $\longrightarrow r$ & $\mathrm{ng} / \mathrm{vaso}$ & - & \multicolumn{2}{|c|}{$\begin{array}{c}\mathrm{g}^{2} \text { matéria seca } \mathrm{mg}^{-1} \\
\text { nutriente }\end{array}$} & $\begin{array}{c}\mu \mathrm{mol} \mathrm{NO}_{2}-\mathrm{h}^{-1} \\
\mathrm{~g}^{-1} \text { matéria fresca }\end{array}$ & $\begin{array}{c}\mu \mathrm{mol} \mathrm{GH^{(1) }} \mathrm{h}^{-1} \\
\mathrm{~g}^{-1} \text { matéria fresca }\end{array}$ & $\mu \mathrm{g} \mathrm{mg}^{-1}$ \\
\hline $\begin{array}{l}75 \% \mathrm{NO}_{3}: 25 \% \mathrm{NH}_{4} \\
\left(126 \mathrm{mg} \mathrm{semana}^{-1} \text { de } \mathrm{N}\right)\end{array}$ & $1,59 \mathrm{~b}$ & $48,40 \mathrm{a}$ & $12,79 \mathrm{a}$ & $8,03 \mathrm{a}$ & $0,10 \mathrm{~b}$ & $0,64 \mathrm{a}$ & $1,93 \mathrm{a}$ & $7,89 \mathrm{~b}$ & $50,31 \mathrm{a}$ \\
\hline $\begin{array}{l}25 \% \mathrm{NO}_{3}: 75 \% \mathrm{NH}_{4} \\
\left(126 \mathrm{mg} \mathrm{semana}^{-1} \text { de } \mathrm{N}\right)\end{array}$ & $1,71 \mathrm{a}$ & $54,21 \mathrm{a}$ & $12,42 \mathrm{a}$ & $7,98 \mathrm{a}$ & $0,09 \mathrm{~b}$ & $0,71 \mathrm{a}$ & $1,31 \mathrm{~b}$ & $9,78 \mathrm{a}$ & $35,73 \mathrm{~b}$ \\
\hline $\begin{array}{l}50 \% \mathrm{NO}_{3}: 50 \% \mathrm{NH}_{4} \\
\left(12,6 \mathrm{mg} \mathrm{semana}^{-1} \text { de } \mathrm{N}\right)\end{array}$ & $1,00 \mathrm{c}$ & $17,09 \mathrm{~b}$ & $6,83 \mathrm{~b}$ & $5,34 \mathrm{~b}$ & $0,14 \mathrm{a}$ & $0,49 \mathrm{~b}$ & $0,56 \mathrm{c}$ & $5,05 \mathrm{c}$ & $56,43 \mathrm{a}$ \\
\hline
\end{tabular}

(1) GH: glutamil hidroximato. Médias seguidas pela mesma letra não diferem entre si, a $5 \%$, pelo teste de Duncan.

aumento nos teores de $\mathrm{N}$ em plantas inoculadas com Azospirillum spp. é comumente relatado, podendo ser resultado tanto da fixação biológica de $\mathrm{N}_{2}$, quanto dos mecanismos de promoção do crescimento, que podem incrementar a capacidade das plantas em absorver este nutriente (Dobbelaere et al., 2001).

$\mathrm{O}$ acúmulo de $\mathrm{P}$ na parte aérea não diferiu com o predomínio da forma nítrica ou amoniacal, mas houve redução significativa na quantidade acumulada, quando a proporção igual das formas de $\mathrm{N}$, na sua menor dose, foi aplicada (Quadro 3). A maior ou menor disponibilidade de $\mathrm{N}$ pode exercer efeito na assimilação de $\mathrm{P}$ e interações sinergísticas entre esses nutrientes já foram identificadas na cultura do milho (Machado et al., 2004). Houve diferenças entre os híbridos em relação ao acúmulo de $\mathrm{P}$ nas raízes, em que o híbrido $\mathrm{H} 1$ apresentou maior conteúdo deste nutriente (Quadro 4). Não se verificou diferença entre plantas de tratamentos inoculados e não inoculados no acúmulo de $\mathrm{P}$ na parte aérea ou nas raízes (Quadro 2).

Dentre os diferentes regimes, o maior índice de utilização de $\mathrm{N}$ foi obtido quando se utilizou a menor dose desse nutriente, com igual proporção entre nitrato e amônio (Quadro 3). Segundo Fernandes et al. (2005), geralmente, o aproveitamento de $\mathrm{N}$ decresce com o aumento das doses aplicadas, uma vez que o suprimento deste nutriente excede as necessidades da cultura. O híbrido $\mathrm{H} 1$ apresentou-se mais eficiente na utilização de N e P (Quadro 4). Essas diferenças entre genótipos de milho quanto à eficiência de utilização de nutrientes normalmente são observadas em outros trabalhos (Machado et al., 2001; Fernandes et al., 2005). Não houve efeito da inoculação com bactérias diazotróficas na eficiência de utilização de N. Isso se deu, de forma geral, para os dois híbridos e em qualquer regime de fornecimento de $\mathrm{N}$ (Quadro 2).
Ao contrário do observado para a eficiência de utilização de $\mathrm{N}$, para o $\mathrm{P}$, os maiores índices foram obtidos quando a maior dose de $\mathrm{N}$ foi fornecida, independentemente da forma predominante (Quadro 3). No trabalho de Machado et al. (2004), também foi observado que, à medida que se aumentou a dose de $\mathrm{N}$ aplicada, maior foi a eficiência de utilização de P. Para os dois híbridos e em qualquer regime de fornecimento de $\mathrm{N}$, não houve efeito da inoculação com bactérias diazotróficas na eficiência de utilização de $\mathrm{P}$ (Quadro 2).

Observou-se que, com o predomínio de nitrato, a atividade da enzima NR foi mais alta e, com o predomínio da forma amoniacal, a atividade da GS foi mais elevada (Quadro 3). Resultados similares foram encontrados por Magalhães et al. (1993). Não houve diferença significativa entre os genótipos para a atividade das duas enzimas avaliadas (Quadro 2), porém, na literatura, a variabilidade genética para a atividade da NR (Purcino et al., 1990) e da GS (Magalhães \& Machado, 1995) é relatada. Resultados similares aos deste estudo foram encontrados por Majerowicz et al. (2002), que também não observaram diferenças nas atividades da GS e da NR em sete genótipos de milho.

Apesar de outros trabalhos citarem o efeito da inoculação com Azospirillum na atividade das enzimas NR (Garcia de Salomone \& Döbereiner, 1996) e GS (Machado et al., 1998a), neste estudo, não se observou tal efeito (Quadro 2). Na verdade, a inconsistência em trabalhos de inoculação com Azospirillum é bastante conhecida e variações no ambiente, solo ou substrato, nas plantas e nos componentes da microflora são consideradas como responsáveis por esta variação de respostas à inoculação entre diferentes experimentos (Dobbelaere et al., 2001). 
Quadro 4. Comportamento de dois híbridos intervarietais de milho em relação à produção de matéria seca (MSR) e conteúdo de fósforo (PR) nas raízes e eficiência de utilização de N (EUN) e P (EUP). As plantas foram cultivadas em casa de vegetação e colhidas 25 dias após o plantio

\begin{tabular}{lcccc}
\hline Híbridos intervarietais de milho & MSR $^{(1)}$ & $\mathbf{P R}^{(1)}$ & $\mathbf{E U N}^{(1)}$ & $\mathbf{E U P}^{(1)}$ \\
\hline & $\mathrm{g} / \mathrm{vaso}$ & $\mathrm{mg} / \mathrm{vaso}$ & $\mathrm{g}^{2}{\text { matéria seca } \mathrm{mg}^{-1} \mathrm{P}-}^{0,12}$ & 0,65 \\
H1 (Carioca x Eldorado) & 0,86 & 1,30 & 0,10 & 0,57 \\
H2 (Palha Roxa x Sol da Manhã) & 0,75 & 1,09 & \\
\hline
\end{tabular}

(1) Diferenças significativas pelo teste $\mathrm{F}$ a $5 \%$.

Quadro 5. Efeito da inoculação com Azospirillum amazonense sobre a produção de matéria seca (MSR) e conteúdo de N (NR) de raízes de plantas de milho cultivadas em casa de vegetação e colhidas 25 dias após o plantio

\begin{tabular}{ccc}
\hline Inoculação & MSR $^{(1)}$ & $\mathbf{N R}^{(1)}$ \\
\hline & $\mathrm{g} / \mathrm{vaso}$ & $\mathrm{mg} / \mathrm{vaso}$ \\
Plantas inoculadas com A. amazonense & 0,86 & 11,69 \\
Plantas não inoculadas & 0,75 & 9,68 \\
\hline
\end{tabular}

${ }^{(1)}$ Diferenças significativas pelo teste $\mathrm{F}$ a $5 \%$.

Não houve efeito dos genótipos ou da inoculação sobre a concentração dos açúcares solúveis totais (AST) analisados nas raízes (Quadro 2). A concentração destes açúcares foi diminuída quando predominou a forma amoniacal na solução nutritiva (Quadro 3). Magalhães et al. (1993) também notaram o efeito do $\mathrm{NH}_{4}{ }^{+}$na redução da concentração dos AST nos quatro genótipos de milho por eles testados. Neste caso, a redução nos teores de AST acontece, porque os esqueletos de $\mathrm{C}$ devem ser rapidamente utilizados para a assimilação do $\mathrm{NH}_{4}{ }^{+}$, que é tóxico, quando acumulado nos tecidos, em aminoácidos.

\section{CONCLUSÕES}

1. O híbrido H1 (Carioca x Eldorado) confirmou sua eficiência observada em avaliações preliminares em campo, produzindo maior quantidade de matéria seca, acumulando mais $\mathrm{P}$ nas raízes e apresentando maiores índices de eficiência de utilização de $\mathrm{N}$ e P.

2. A inoculação com $A$. amazonense promoveu maior produção de matéria seca e acúmulo de $\mathrm{N}$ nas raízes.

3. O regime de $\mathrm{N}$, variando doses e proporções de $\mathrm{NH}_{4}{ }^{+}$e $\mathrm{NO}_{3}^{-}$, foi o fator que influenciou o maior número de características avaliadas com reflexo sobre a produção de matéria seca da parte aérea, conteúdo de $\mathrm{N}$ da parte aérea e raízes, conteúdo de $\mathrm{P}$ da parte aérea, eficiência de utilização de $\mathrm{N}$ e $\mathrm{P}$, atividade da nitrato redutase, atividade da glutamina sintetase e açúcares solúveis totais.

\section{AGRADECIMENTOS} 03-0.

Ao CNPq, pelo apoio financeiro ao projeto $n^{\circ} 478026 /$

Ao Professor Jorge Vega e aos funcionários do Laboratório de Bioquímica de Plantas e casa de vegetação do Departamento de Fisiologia Vegetal da Unicamp, pelo apoio na realização do experimento.

\section{LITERATURA CITADA}

ALFOLDI, Z.; PINTER, L. \& FEIL, B. Accumulation and partitioning of biomass and soluble carbohydrates in maize seedlings as affected by source of nitrogen, nitrogen concentration and cultivar. J. Plant Nutr., 15:2567-2583, 1992.

BALDANI, J.I.; CARUSO, L.; BALDANI, V.L.D.; GOI, S.R. \& DÖBEREINER, J. Recent advances in BNF with nonlegume plants. Soil Biol. Biochem., 29:911-922, 1997.

BALDANI, J.I.; AZEVEDO, M.S.; REIS, V.M.S.; TEIXEIRA, K.R.; OLIVARES, F.L.; GOI, S.R.; BALDANI, V.L.D. \& DÖBEREINER, J. Fixação biológica de nitrogênio em gramíneas: Avanços e aplicações. In: SIQUEIRA, J.O.; MOREIRA, F.M.S.; LOPES, A.S.; GUILHERME, L.R.G.; FAQUIN, V.; FURTINI NETO, A.E. \& CARVALHO, J.G., eds. Inter-relação fertilidade, biologia do solo e nutrição de plantas. Viçosa, MG, SBCS/Lavras, UFLA/DCS, 1999. p.621-666.

BASHAN, Y. \& HOLGUIN, G. Azospirillum-plant relationships: Environmental and physiological advances (1990-1996). Can. J. Microbiol., 43:103-121, 1997.

BIELESKI, R.L. \& TURNER, N.A. Separation and estimation of amino acids in crude plant extracts by thin-layer electrophoresis and cromatography. Anal. Biochem., 17:278-293, 1966. 
DOBBELAERE, S.; CROONENBORGHS, A.; THYS, A.; PTACEK, D.; VANDERLEYDEN, J.; DUTTO, P.; LABANDERA-GONZALEZ, C.; CABALLERO-MELLADO, J.; AGUIRRE, J.F.; KAPULNIK, Y.; BRENER, S.; BURDMAN, S.; KADOURI, D.; SARIG, S. \& OKON, Y. Response of agronomically important crops to inoculation with Azospirillum. Aust. J. Plant Physiol., 28:871-879, 2001.

EMPRESA BRASILEIRA DE PESQUISA AGROPECUÁRIA EMBRAPA. Manual de análises químicas de solos, plantas e fertilizantes. Brasília, Embrapa Comunicação para Transferência de Tecnologia, 1999. 370p.

FANCELLI, A.L. \& DOURADO-NETO, D. Produção de milho. Guaíba, Agropecuária, 2000. 360p.

FANCELLI, A.L. Milho: ambiente e produtividade. In: FANCELLI, A.L. \& DOURADO-NETO, D., eds. Milho: Estratégias de manejo para alta produtividade. Piracicaba, Escola Superior de Agricultura Luiz de Queiroz, 2003. p.174-197.

FERNANDES, F.C.S.; BUZETTI, S.; ARF, O. \& ANDRADE, J.A.C. Doses, eficiência e uso de nitrogênio por seis cultivares de milho. R. Bras. Milho Sorgo, 4:195-204, 2005.

FERREIRA, M.C.B.; FERNANDES, M.S. \& DÖBEREINER, J. Role of Azospirillum brasilense nitrate reductase in nitrate assimilation by wheat plants. Biol. Fert. Soils, 4:47-53, 1987.

GARCIA DE SALOMONE, I.E. \& DÖBEREINER, J. Maize genotype effects on the response to Azospirillum inoculation. Biol. Fert. Soils, 21:193-196, 1996.

GARCIA DE SALOMONE, I.E.; DÖBEREINER, J.; URQUIAGA, S. \& BODDEY, R.M. Biological nitrogen fixation in Azospirillum strain-maize genotype associations as evaluated by the $15 \mathrm{~N}$ isotope dilution technique. Biol. Fert. Soils, 23:249-256, 1996.

GRAHAM, D. \& SMYDZUC, J. Use of anthrone in the quantitative determination of hexose phosphates. Anal. Biochem., 11:246-255, 1965.

LEE, K.B.; PARK, T.G. \& SONG, S.D. Effects of Azospirillum amazonense Y1 on the growth of corn. Korean J. Bot., 32:137-144, 1989.

MACHADO, A.T.; SODEK, L.; DÖBEREINER, J. \& REIS, V.M. Efeito da adubação nitrogenada e da inoculação com bactérias diazotróficas no comportamento bioquímico da cultivar de milho Nitroflint. Pesq. Agropec. Bras., 33:961970, 1998a.

MACHADO, A.T.; PEREIRA, M.B.; PEREIRA, M.E.; MACHADO, C.T.T. \& MÉDICE, L.O. Avaliação de variedades locais e melhoradas de milho em diferentes regiões do Brasil. In: SOARES, A.C.; MACHADO, A.T.; SILVA, B.M. \& von der WEID, J.M., eds. Milho crioulo: Conservação e uso da biodiversidade. Rio de Janeiro, ASPTA, 1998b. p.93-106

MACHADO, A.T. The collaborative development of stresstolerant maize varieties in Rio de Janeiro, Brazil. In ALMEKINDERS, C. \& DE BOEF, W., eds. Encouragin diversity: The conservation and development of plant genetic resources. London, Intermediate Technology Publications, 2000. p.199-202.

MACHADO, A.T. \& FERNANDES, M. Participatory maize breeding for low nitrogen tolerance. Euphytica, 122:567. 573, 2001.
MACHADO,A.T.; ARCANJO, J.N.; MACHADO,C.T.T.; NASS, L.L. \& BETTERO, F.C.R. Mejoramiento participativo en maís: Su contribución en el empoderamiento comunitário en el Município de Muqui, Brasil. Agron. Mesoamericana, 17:393-405, 2006.

MACHADO, C.T.T.; FURANI, A.M.C. \& MACHADO, A.T. Índices de eficiência de variedades locais e melhoradas de milho ao fósforo. Bragantia, 60:225-238, 2001.

MACHADO, C.T.T.; MACHADO, A.T.; REIS JR, F.B. \& VILELA, A.L. Acumulação de nitrogênio, fósforo e zinco e índices de eficiência de utilização e translocação de nutrientes em milho submetido a dois níveis de adubação nitrogenada. In: FertBIO 2004. REUNIÃO BRASILEIRA DE FERTILIDADE DO SOLO E NUTRIÇÃO DE PLANTAS, 26.; REUNIÃO BRASILEIRA SOBRE MICORRIZAS, 10.; SIMPÓSIO BRASILEIRO DE MICROBIOLOGIA DO SOLO, 7.; REUNIÃO BRASILEIRA DE BIOLOGIA DO SOLO: AVALIAÇÃO DAS CONQUISTAS: BASE PARA ESTRATÉGIAS FUTURAS, 5., Lages, 2004. Viçosa, MG, SBCS/UDESC, 2004. CD-ROM.

MAGALHÃES, J.R. \& MACHADO, A.T. Biochemical parameters selecting maize for nitrogen assimilation efficiency under stress conditions. In: MACHADO, A.T.; MAGNAVACA, R.; PANDEY, S. \& SILVA, A.F., eds. SIMPÓSIO INTERNACIONAL SOBRE ESTRESSE AMBIENTAL: o milho em perspectiva. Belo Horizonte, 1995. p.346-367.

MAGALHÃES, J.R.; MACHADO, A.T.; FERNANDES, M.S. \& SILVEIRA, J.A.G. Nitrogen assimilation efficiency in maize genotypes under ammonia stress. R. Bras. Fisiol. Veg., 5:163-166, 1993.

MAJEROWICZ, N.; PEREIRA, J.M.S.; MEDICI, L.O.; BISON, O.; PEREIRA, M.B. \& SANTOS JÚNIOR, U.M. Estudo da eficiência de uso do nitrogênio em variadedes locais e melhoradas de milho. R. Bras. Bot., 25:129-136, 2002.

OKON, Y. \& VANDERLEYDEN, J. Root-associated Azospirillum species can stimulate plants. ASM News, 63:364-370, 1997.

PURCINO, A.A.C.; MAGNAVACA, R.; MACHADO, A.T.; MARRIEL, I.E. \& MAGALHÃES, J.R. Redutase do nitrato em genótipos antigos e modernos de milho. In: SIMPÓSIO BRASILEIRO SOBRE NITROGÊNIO EM PLANTAS, 1., Rio de Janeiro, 1990. Anais. Universidade Federal Rural do Rio de Janeiro, 1990. p.491-492.

ROLIM, L.; SANTOS, A.B.; MACHADO, C.T.T.; MENDES, I.C.; MACHADO, A.T. \& REIS JUNIOR, F.B. Produção de ácido indolacético e promoção do crescimento de plantas de milho por estirpes de Herbaspirillum seropedicae e Azospirillum Amazonense. In: CONGRESSO BRASILEIRO DE CIÊNCIA DO SOLO: SOLOS, SUSTENTABILIDADE E QUALIDADE AMBIENTAL, 33., Recife, 2005. Anais. Recife, 2005. CD-ROM.

SILVA, M.F. Avaliação da colonização por Azospirillum spp. na cultura do milho (Zea Mays L.) utilizando a técnica do ELISA. Seropédica, Universidade Federal Rural do Rio de Janeiro, 2005. 58p. (Tese de Mestrado)

SOARES, A.C.; MACHADO, A.T.; SILVA, B.M. \& von der WEID, J.M. Milho Crioulo: Conservação e uso da biodiversidade. Rio de Janeiro, AS-PTA, 1998. 185p. 